\title{
An alternative way to measure the depth of invasion of vulvar squamous cell carcinoma in relation to prognosis
}

\author{
Loes CG van den Einden ${ }^{1}$, Leon FAG Massuger ${ }^{1}$, Johanna K Jonkman ${ }^{1}$, Peter Bult ${ }^{2}$, \\ Joanne A de Hullu ${ }^{1}$ and Johan Bulten ${ }^{2}$ \\ ${ }^{1}$ Department of Obstetrics and Gynaecology, Radboud University Medical Center, Nijmegen, \\ The Netherlands and ${ }^{2}$ Department of Pathology, Radboud University Medical Center, Nijmegen, \\ The Netherlands
}

\begin{abstract}
Depth of invasion is an important prognostic factor for patients with vulvar squamous cell carcinoma. The aim of this study was to identify the most optimal method of measuring the depth of invasion in relation to the individual outcome in patients with vulvar squamous cell carcinoma. Data of 175 consecutive patients with a primary vulvar squamous cell carcinoma with known lymph node status, treated in the Radboud University Medical Center, the Netherlands (2000-2010), were stored in a database. At pathology review of $148(85 \%)$ cases, depth of invasion was measured using the conventional and alternative methods. Clinical and pathological characteristics of patients with a change in FIGO stage were compared with those without a change in stage. In 148 vulvar squamous cell carcinoma patients, the median depth of invasion was shown to be decreased from $5.5 \mathrm{~mm}$ (range 1.1-20) using the conventional method to $3.6 \mathrm{~mm}$ (range $0.2-20$ ) using the alternative method $(P<0.05)$. This led to a change in the FIGO stage in 13 of the $148(9 \%)$ patients and a change in depth of invasion from 3.5 to $0.2 \mathrm{~mm}$ in one patient (1\%) with FIGO stage IIIA. Of all 69 stage 1B patients, $13(19 \%)$ were downstaged to stage IA. The downstaged patients developed less recurrences (15\% vs $39 \%$ ) and had a higher disease-specific survival $(100 \%$ vs $84 \%)$ compared with the patients who remained FIGO stage IB. Using the alternative method for measuring the depth of invasion in tumors of vulvar squamous cell carcinoma patients, $19 \%$ of the patients with a FIGO stage IB tumor might be treated without groin surgery resulting in less treatment-related morbidity. The results are promising but more prospective data on a higher number of patients are necessary.

Modern Pathology (2015) 28, 295-302; doi:10.1038/modpathol.2014.103; published online 5 September 2014
\end{abstract}

Vulvar squamous cell carcinoma is a rare disease that mainly affects elderly women. ${ }^{1}$ For decades, radical surgery (radical vulvectomy with bilateral inguinofemoral lymphadenectomy) has been the standard treatment for the early-stage disease with a favorable prognosis but with the consequence of impressive morbidity such as wound-healing problems, lymph edema, and psychosexual impact. ${ }^{2,3}$

Over the past years, efforts have been made to individualize the treatment of patients with vulvar squamous cell carcinoma and define subgroups of patients who may be treated by less radical procedures.

Correspondence: Dr LCG van den Einden, MD, Department of Obstetrics and Gynaecology, Radboud University Medical Center, PO Box 9101, Nijmegen 6500 HB, The Netherlands.

E-mail: loes.vandeneinden@radboudumc.nl

Received 25 February 2014; accepted 14 May 2014; accepted 15 May 2014; published online 5 September 2014
Until now, there are some generally accepted modifications for patients with macroinvasive tumors (>1-mm invasion): separate incisions instead of 'en bloc' approach; wide local excision instead of radical vulvectomy; unilateral lymphadenectomy in case of a lateralized tumor; ${ }^{4}$ and a sentinel lymph node procedure in patients with a unifocal tumor $<4 \mathrm{~cm}$ without abnormal groin nodes at imaging. ${ }^{5} \mathrm{In}$ case of microinvasive tumors $(\leq 1-\mathrm{mm}$ invasion and a maximum diameter of $2 \mathrm{~cm}$ ), patients are treated with a wide local excision only, and treatment of the groins can be safely omitted ${ }^{6}$ because only $<1 \%$ of these superficially invasive vulvar squamous cell carcinoma metastasize to the groins. ${ }^{7,8}$ This is in contrast to tumors with $>1-\mathrm{mm}$ invasion, which have a risk of nodal metastases of up to $34 \% .{ }^{7,9}$ So far, patients with a stage IA tumor are the only group of vulvar squamous cell carcinoma patients who will not need to undergo treatment of the groins. 
As the depth of invasion guides the mode of treatment of vulvar squamous cell carcinoma patients, it is important that pathologists use a uniform measuring method that reflects the best clinical outcome. In the past, several methods have been described by Wilkinson, ${ }^{7}$ which are shown in Figure 1. In 1984 the International Society for the Study of Vulvo-Vaginal Disease (ISSVD) and the International Society of Gynecological Pathologists (ISGYP) recommended to define the depth of invasion as follows: from the epithelial junction of the most superficial adjacent dermal papilla to the deepest point of invasion (Method A in Figure 1). ${ }^{10}$ Reasons for choosing this method are not scientific but are mainly based on the following practical issues: (1) the adjacent dermal papilla can be found in all sites of the vulva, (2) it is not altered by variations in the depth of rete ridges, and (3) the measurement is not significantly influenced by hyperkeratosis, tumor surface ulceration, or adjacent epithelial hyperplasia.7,10,11 Only Kurzl et $a 1^{12}$ compared several methods of measurement, searching for the clearest prognostic differentiation between groups of patients. They found that depending on the cutoff point used for the depth of invasion $(2,3$, or $5 \mathrm{~mm}$ ), different measuring methods led to different (disease-free) survival. Unfortunately, tumors were not classified up and over $1 \mathrm{~mm}$, and the lymph node status was not available in this study as all patients had undergone groin irradiation.

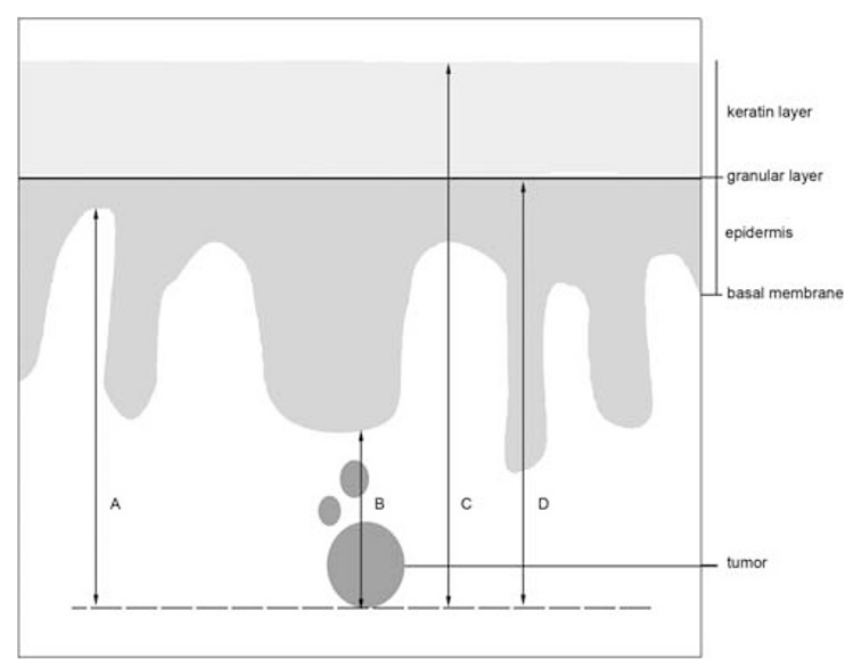

Figure 1 Schematic drawing of the skin with different methods of measuring the depth of invasion of vulvar squamous cell carcinoma. Method A (conventional method in this study): measurement from the epithelial junction of the most superficial adjacent dermal papillae to the deepest point of invasion, method recommended by the ISSVD and the ISGYP. Method B (alternative method in this study): measurement from the most adjacent dysplastic abnormal rete ridge to the deepest point of invasion, modified from one of the measuring methods described by Wilkinson et $a l^{7}$. Method C: measurement from the surface to the deepest point of invasion=tumor thickness. Method D: measurement from the granular layer to the deepest point of invasion (modified from Wilkinson et $a l^{7}$ ).
On the basis of our experience with the clinical outcome of patients with vulvar squamous cell carcinoma and on the basis of the fact that there is no scientific basis for choosing the current measuring method for the depth of invasion, it can be argued whether an alternative method of measuring depth of invasion may give a better reflection of the prognosis. Therefore, the aim of this study was to identify the most optimal method of measuring the depth of invasion in relation to the individual outcome in patients with vulvar squamous cell carcinoma.

\section{Materials and methods}

\section{Patients}

All patients with a primary vulvar squamous cell carcinoma and known lymph node status (based on results of inguinofemoral lymphadenectomy or sentinel lymph node procedure, FIGO stage $\geq$ IB) diagnosed between 2000 and 2010 in the Radboud University Medical Centre (RUMC) were included in this study. Data of the patients were collected from medical charts, electronic patient files, and pathology reports, and were stored in a database. Patient characteristics included age, date of diagnosis, FIGO stage (2009), treatment modality, and recurrences. Pathological characteristics included tumor size, depth of invasion of the tumor, multifocality, nodal status, and presence of lymphovascular invasion. Furthermore, information on vital status, date, and the cause of death was obtained until the 1st September 2013.

\section{Pathologic Assessment}

Available hematoxylin and eosin (H\&E) slides of surgical resections of all patients were retrieved and revised by an expert gynecopathologist (JB), independently and unaware of the clinical course of the patients. The depth of invasion was measured using a measuring ocular and two different methods were addressed: the conventional method (measures from the epithelial junction of the most superficial dermal papilla to the deepest point of tumor invasion, method A Figure 1) and the alternative method (measures from the basement membrane of the deepest adjacent (dysplastic) tumor-free rete ridge to the deepest point of invasion, method B Figure 1). Reasons for choosing this particular alternative method were as follows: (1) it is also used in measuring invasion depth in other cancer sites (such as in cervical $^{13}$ and larynx/trachea ${ }^{14}$ ), (2) logically, tumor cells will originate from the nearest rete ridges instead of the most superficial one, (3) besides the conventional method, it is the only method described by Wilkinson ${ }^{7}$ that is not altered by variation of rete ridges or influenced by hyperkeratosis, ulceration, or epithelial hyperplasia. 
In cases where the deepest rete ridge was deeper than the tumor, the most adjacent basement membrane of the rete ridge was used to measure. Besides depth of invasion, grade of differentiation and lymphovascular invasion were determined. In case the tumor was multifocal, the deepest lesion was selected and in case the depth of invasion was $\leq 1 \mathrm{~mm}$, all lesions were assessed. In cases where the depth of invasion was $>1 \mathrm{~mm}$ using the conventional measuring method but $\leq 1 \mathrm{~mm}$ using the alternative method, the slides of the biopsies taken before primary surgery were retrieved and assessed using both measuring methods. On the basis of the depth of invasion measured with the alternative method and the characteristics known before (tumor of $\leq 2 \mathrm{~cm}$ diameter) and after groin surgery (groin metastasis yes/no), patients were given a new FIGO stage. ${ }^{15}$

Patients who were included in this study underwent a sentinel lymph node procedure in case the tumor diameter was $<4 \mathrm{~cm}$ and the inguinoferoral lymph nodes were clinically nonsuspicious. The pathologic assessment of the sentinel node(s) was performed according to the standard protocol used in the GROINSS-V study. ${ }^{5}$ In short, ultrastaging was performed by sectioning the lymph nodes at 2- to 3mm intervals. In addition, pairs of sections were cut at $350-\mu \mathrm{m}$ intervals and stained with $\mathrm{H} \& \mathrm{E}$ and immunostained with cytokeratin 1\% AE 1/3 antikeratin solution (Boehringer Mannheim, Mannheim, Germany).

\section{Statistical Analysis}

The median invasion depths measured using the conventional and alternative methods were compared using the Wilkinson-signed rank test. Clinical and pathological characteristics of patients with a change in the FIGO stage were compared with those without a change in the FIGO stage, using the Fisher's exact test and the $\chi^{2}$ test. Furthermore, for these patient groups the overall survival and disease-specific survival were calculated using the Kaplan-Meier method. All analyses were performed using the SPSS software, version 20 (SPSS Inc, Chicago, IL, USA). P-values less than 0.05 were considered to be statistically significant.

\section{Results}

\section{Population Description}

For this study, 175 patients met the inclusion criteria: 27 cases (15\%) were excluded because the H\&E slides could not be retrieved $(n=26)$ or because of a low quality of the slides for review $(n=1)$. Finally, data from the 148 patients were enrolled in the study. The median age of the study population was 72 years (range 36-91). The median time of follow-up was 54 months (range 2 weeks to
156 months). Tumor-related characteristics are listed in Table 1.

\section{Comparative Measurement of Tumor Invasion}

Of all the 148 patients, the depth of invasion was measured using the conventional and the alternative method. The invasion depth of 13 patients $(9 \%)$ did not change; of 80 patients $(54 \%)$ the depth decreased $0.1-1 \mathrm{~mm}$; of 20 patients (14\%) the depth decreased 1.1-2 $\mathrm{mm}$; and of 35 patients $(24 \%)$ the depth decreased 2.1-8.1 mm. The median depth of

Table 1 Characteristics of 148 women diagnosed with vulvar squamous cell carcinoma treated in the Radboud University Medical Center (2000-2010)

\begin{tabular}{|c|c|c|}
\hline Characteristics & $N$ & $\%$ \\
\hline \multicolumn{3}{|l|}{ FIGO stage (2009) } \\
\hline IB & 69 & 47 \\
\hline II & 3 & 2 \\
\hline III & 73 & 49 \\
\hline IV & 3 & 2 \\
\hline \multicolumn{3}{|l|}{ Tumor grade } \\
\hline I & 24 & 16 \\
\hline II & 78 & 53 \\
\hline III & 46 & 31 \\
\hline \multicolumn{3}{|l|}{ Lymphovascular invasion } \\
\hline Yes & 37 & 25 \\
\hline No & 111 & 75 \\
\hline \multicolumn{3}{|l|}{ Multifocality } \\
\hline No & 120 & 81 \\
\hline Yes & 28 & 19 \\
\hline \multicolumn{3}{|l|}{ Positive lymph nodes } \\
\hline No & 72 & 49 \\
\hline Yes & 76 & 51 \\
\hline \multicolumn{3}{|l|}{ Treatment } \\
\hline \multicolumn{3}{|l|}{ Local surgery } \\
\hline Wide local excision & 101 & 68 \\
\hline Radical vulvectomy & 43 & 29 \\
\hline Posterior exenteration & 4 & 3 \\
\hline \multicolumn{3}{|l|}{ Groin surgery } \\
\hline Sentinel lymph node procedure & 52 & 35 \\
\hline Dissection & 72 & 49 \\
\hline Sentinel lymph node procedure + dissection & 24 & 16 \\
\hline Adjuvant radiotherapy & 47 & 32 \\
\hline \multicolumn{3}{|l|}{ Recurrence during follow-up } \\
\hline None & 92 & 62 \\
\hline Local & 47 & 32 \\
\hline Local + groin & 1 & 1 \\
\hline Groin & 8 & 5 \\
\hline \multicolumn{3}{|l|}{ Died during follow-up } \\
\hline No & 83 & 56 \\
\hline Yes & 65 & 44 \\
\hline Of intercurrent disease & 21 & 14 \\
\hline Of disease & 31 & 21 \\
\hline Of unknown cause & 13 & 9 \\
\hline
\end{tabular}

FIGO, International Federation of Gynecology and Obstetrics; N, number of cases. 
Table 2 Comparison of FIGO stages of 148 vulvar squamous cell carcinoma patients according to the depth of invasion measured with the conventional and the alternative method

\begin{tabular}{crrrrrrrr}
\hline & \multicolumn{7}{c}{ FIGO stage_conventional method } \\
\cline { 2 - 8 } & IA & IB & II & IIIA & IIIB & IIIC & IV & Total \\
\hline FIGO stage_-alternative method & & & & \\
IA & - & $\mathbf{1 3}^{\mathrm{a}}$ & 0 & $\mathbf{1}^{\mathrm{a}}$ & 0 & 0 & 0 & 14 \\
IB & 0 & 56 & 0 & 0 & 0 & 0 & 0 & 56 \\
II & 0 & 0 & 3 & 0 & 0 & 0 & 0 & 3 \\
IIIA & 0 & 0 & 0 & 43 & 0 & 0 & 0 & 43 \\
IIIB & 0 & 0 & 0 & 0 & 6 & 0 & 0 & 6 \\
IIIC & 0 & 0 & 0 & 0 & 0 & 23 & 0 & 23 \\
IV & 0 & 0 & 0 & 0 & 0 & 0 & 3 & 3 \\
Total & 0 & 69 & 3 & 44 & 6 & 23 & 3 & 148 \\
\hline
\end{tabular}

FIGO, International Federation of Gynecology and Obstetrics. a Downstaged.

invasion using the conventional method was $5.5 \mathrm{~mm}$ (range 1.1-20); using the alternative method the median depth of invasion was $3.6 \mathrm{~mm}$ (range $0.2-$ 20), which is significantly lower (Wilcoxon-signed rank test, $P<0.05)$.

On the basis of the depth of invasion measured with the alternative method and the tumor characteristics known before (tumor diameter) and after groin surgery (groin metastasis yes/no), patients were given a new FIGO stage. Table 2 displays the changes in the FIGO stage. Of 134 patients (91\%), the FIGO stage did not change and of $14(9 \%)$ it did change. Thirteen of sixty-nine (19\%) patients with FIGO stage IB (lesions $>2 \mathrm{~cm}$ in size or with invasion $>1.0 \mathrm{~mm}$, confined to the vulva/perineum, with negative nodes) were downstaged to FIGO stage IA. In 1 of $44(2 \%)$ patients with FIGO stage IIIA (tumor confined to the vulva or adjacent spread to the lower urethra, the vagina, or the anus, with one lymph node metastasis $\geq 5 \mathrm{~mm}$ or one or two lymph node metastases $<5 \mathrm{~mm}$ ) the depth of invasion changed from $3.5 \mathrm{~mm}$ to $<1 \mathrm{~mm}(0.2 \mathrm{~mm})$. This single case showed isolated tumor cells in the sentinel lymph node.

\section{Tumor and Clinical Characteristics of the Patient with FIGO Stage IIIA Vulvar Squamous Cell Carcinoma that Showed a Change in the Depth of Invasion}

The patient was a 49-year-old female with a history of lichen sclerosus and a unifocal lesion on the right labium minus of $2 \mathrm{~cm}$. Microscopic evaluation showed a well-differentiated tumor without presence of lymphovascular invasion. An H\&E-stained slide of the tumor is displayed in Figure 2. The patient was treated with a wide local excision and a sentinel lymph node procedure of the right groin. Three lymph nodes were removed; in the immunohistochemical slides of one node two isolated tumor cells were found (Figure 3). Therefore, the patient

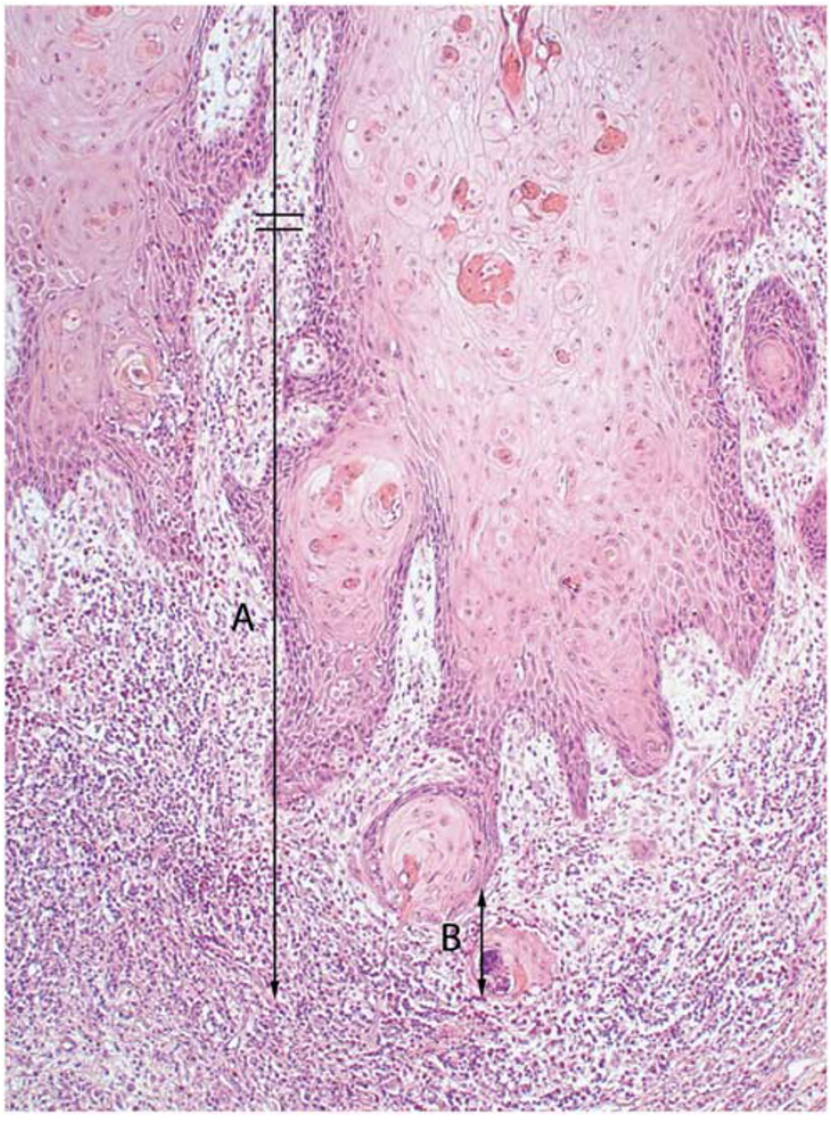

Figure 2 Microscopical slide of the case with FIGO stage IIIA vulvar squamous cell carcinoma in which the depth of invasion changed from 3.5 to $0.2 \mathrm{~mm}$ because of the alternative measuring method. A: measurement of depth of invasion with conventional method; B: measurement of depth of invasion with alternative method.

underwent an unilateral inguinofemoral lymphadenectomy in which eight lymph nodes were removed that showed no metastases. After a follow-up of 120 months, the patient is alive and there is no evidence of disease.

\section{Tumor and Clinical Characteristics of Patients who Changed from FIGO Stage IB to IA and those who Remained FIGO Stage IB}

The median ages of the patients who remained FIGO stage IB $(N=56)$ and who were downstaged $(N=13)$ were 75 and 69 years, respectively. Other characteristics are displayed in Table 3 ; the patients who were downstaged had more often a well-differentiated tumor $(62 \%$ vs $18 \%, P=0.003)$, less lymphovascular invasion ( $0 \%$ vs $16 \%)$, less recurrences (15\% vs $39 \%$ ), and died less frequently because of the vulvar squamous cell carcinoma ( $0 \%$ vs $13 \%)$. The median diameter of the tumors in downstaged patients was $6 \mathrm{~mm}$ (range 2-19 $\mathrm{mm}$ ), in contrast to the patients who were not downstaged with a median diameter of $25 \mathrm{~mm}$ (range $5-63 \mathrm{~mm}$ ). The 


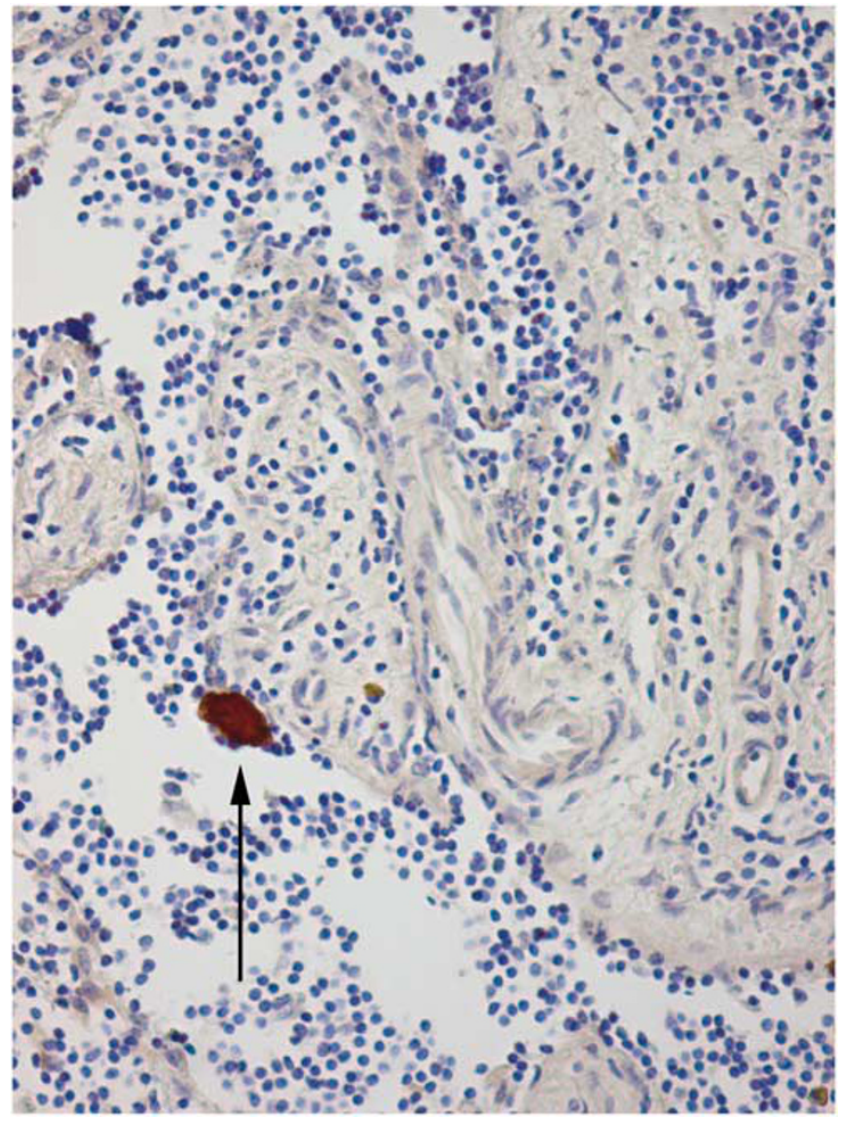

Figure 3 Microscopical slide of the sentinel lymph node of the case with FIGO stage IIIA vulvar squamous cell carcinoma in which the depth of invasion changed from 3.5 to $0.2 \mathrm{~mm}$ because of the alternative measuring method. Arrow: one immunohistochemically positive tumor cell.

median depth of invasion in patients who were downstaged changed from $2.4 \mathrm{~mm}$ (conventional method, range $1.1-5 \mathrm{~mm}$ ) to $0.7 \mathrm{~mm}$ (alternative method, range $0.2-1.0 \mathrm{~mm}$ ), and from $5.6 \mathrm{~mm}$ (conventional method, range $1.7-14 \mathrm{~mm}$ ) to $2.6 \mathrm{~mm}$ (alternative method, range $0.3-13 \mathrm{~mm}$ ) in patients who remained FIGO stage IB. An example of the measurements in a tumor that was downstaged is displayed in Figure 4.

Overall survival and disease-specific survival of patients with the conventional FIGO stage IB at 5 years was $75 \%$ (95\% confidence interval (CI): $64-$ $86 \%$ ) and $88 \%(95 \% \mathrm{Cl}: 79-96 \%)$, respectively. In the group of patients with the alternative FIGO stage IA, the 5-year disease-specific survival was $100 \%$ (95\% Cl: 75-100\%), which is higher compared with the 5-year disease-specific survival of the group of patients with the alternative FIGO stage 1B $(84 \%$; $95 \% \mathrm{Cl} \quad 73-95 \% ; P=0.15)$. The disease-specific survival is shown in Figure 5.

\section{Discussion}

This is the first study that focused on comparing the conventional with an alternative method of measur-
Table 3 Comparison of characteristics between 13 women who were downstaged from FIGO stage IB to IA and 56 women who remained FIGO stage IB with the use of the alternative measuring method for the depth of invasion of vulvar squamous cell carcinoma

\begin{tabular}{|c|c|c|c|c|c|}
\hline \multirow[b]{2}{*}{ Characteristics } & \multicolumn{2}{|c|}{$\begin{array}{l}I B \rightarrow I A \\
(\mathrm{~N}=13)\end{array}$} & \multicolumn{2}{|c|}{$\begin{array}{l}I B=I B \\
(\mathrm{~N}=56)\end{array}$} & \multirow[b]{2}{*}{ P-Value } \\
\hline & $\mathrm{N}$ & $\%$ & $\mathrm{~N}$ & $\%$ & \\
\hline \multicolumn{6}{|l|}{ Tumor grade } \\
\hline I & 8 & 61 & 10 & 18 & \\
\hline II & 4 & 31 & 33 & 59 & \\
\hline III & 1 & 8 & 13 & 23 & $\mathbf{0 . 0 0 3}^{\mathrm{a}}$ \\
\hline \multicolumn{6}{|l|}{ Lymphovascular invasion } \\
\hline Yes & 0 & 0 & 9 & 16 & \\
\hline No & 13 & 100 & 47 & 84 & $0.13^{\mathrm{b}}$ \\
\hline \multicolumn{6}{|l|}{ VIN adjacent to the tumor } \\
\hline No & 3 & 23 & 11 & 20 & \\
\hline Yes & 10 & 77 & 45 & 80 & \\
\hline uVIN & 4 & 31 & 6 & 10 & \\
\hline dVIN & 6 & 46 & 39 & 70 & $0.52^{\mathrm{b}}$ \\
\hline \multicolumn{6}{|l|}{ Multifocality } \\
\hline No & 10 & 77 & 39 & 70 & \\
\hline Yes & 3 & 23 & 17 & 30 & $0.44^{\mathrm{b}}$ \\
\hline \multicolumn{6}{|l|}{ Location } \\
\hline Central & 11 & 85 & 45 & 80 & \\
\hline Lateral $^{\mathrm{C}}$ & 2 & 15 & 11 & 20 & $0.54^{\mathrm{b}}$ \\
\hline \multicolumn{6}{|l|}{ Treatment } \\
\hline \multicolumn{6}{|l|}{ Local surgery } \\
\hline Wide local excision & 12 & 92 & 41 & 73 & \\
\hline Radical vulvectomy & 1 & 8 & 15 & 27 & \\
\hline \multicolumn{6}{|l|}{ Groin surgery } \\
\hline Sentinel lymph node procedure & 9 & 69 & 24 & 43 & \\
\hline Dissection & 4 & 31 & 26 & 46 & \\
\hline $\begin{array}{l}\text { Sentinel lymph node } \\
\text { procedure + dissection }\end{array}$ & 0 & 0 & 6 & 11 & \\
\hline Adjuvant radiotherapy & 0 & 0 & 0 & 0 & NA \\
\hline \multicolumn{6}{|l|}{ Recurrences } \\
\hline No & 11 & 85 & 34 & 61 & \\
\hline Yes & 2 & 15 & 22 & 39 & $0.09^{\mathrm{b}}$ \\
\hline Local & 2 & 15 & 17 & 30 & \\
\hline Groin & 0 & 0 & 4 & 7 & \\
\hline Local + groin & 0 & 0 & 1 & 2 & \\
\hline \multicolumn{6}{|l|}{ Died during follow-up } \\
\hline No & 9 & 69 & 37 & 66 & \\
\hline Yes & 4 & 31 & 19 & 34 & $0.61^{\mathrm{b}}$ \\
\hline Of intercurrent disease & 4 & 31 & 5 & 9 & \\
\hline Of disease & 0 & 0 & 7 & 12.5 & \\
\hline Unknown cause of disease & 0 & 0 & 7 & 12.5 & \\
\hline
\end{tabular}

dVIN, differentiated vulvar intraepithelial neoplasia; FIGO, International Federation of Gynecology and Obstetrics; NA: not applicable; uVIN, usual VIN.

${ }^{\mathrm{a}} \chi^{2}$ test.

bisher's exact test.

${ }^{\mathrm{C}}$ More than $1 \mathrm{~cm}$ of the midline.

ing the depth of invasion in order to find the method corresponding with the most optimal individual outcome in patients with vulvar squamous cell carcinoma. The results of this study show that with the use of the alternative measuring method, from 


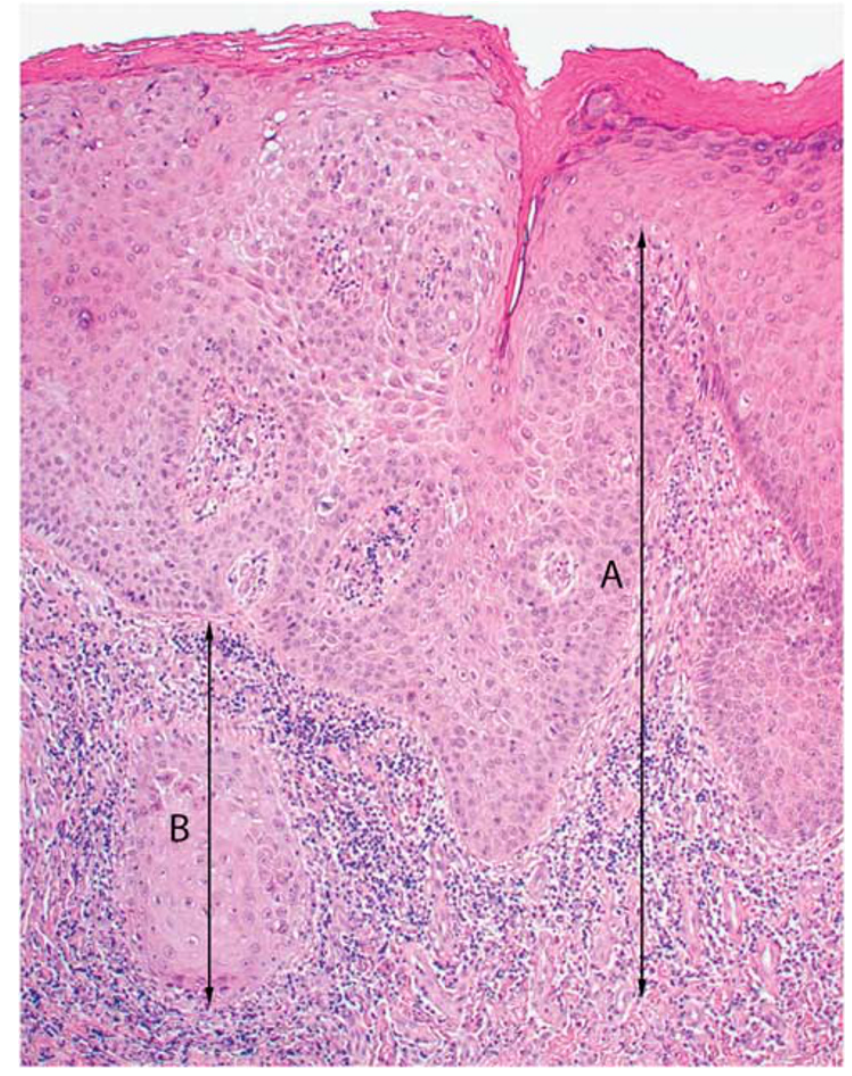

Figure 4 Microscopical slide of a case which was downstaged because of the alternative measuring method of the depth of invasion in vulvar squamous cell carcinoma. A: measurement of depth of invasion with conventional method; B: measurement of depth of invasion with alternative method.

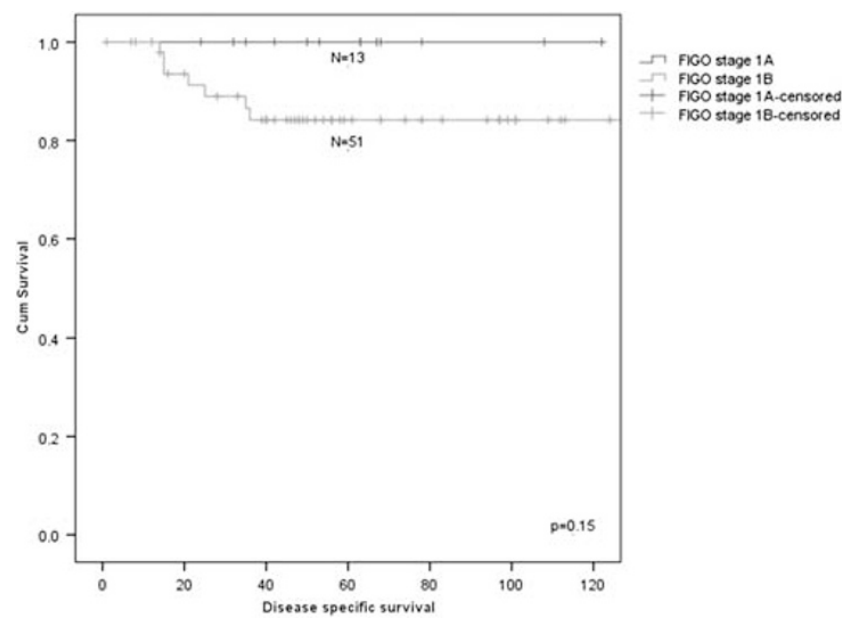

Figure 5 Disease-specific survival of vulvar squamous cell carcinoma patients* with FIGO stage IA vs stage IB after using the alternative measuring method for the depth of invasion, in months. *Five patients were excluded from analysis because the cause of death was unknown; FIGO: International Federation of Gynecology and Obstetrics. the basement membrane of the deepest adjacent tumor-free rete ridge to the deepest point of invasion, $19 \%$ of the patients with a FIGO stage IB tumor were downstaged to FIGO stage IA. These patients showed less recurrences and a higher diseasespecific survival compared with the remaining FIGO stage IB tumors. This downstaged group might be treated without groin surgery. A change in the depth of invasion from 3.5 to $0.2 \mathrm{~mm}$ occurred in one patient $(1 \%)$ with FIGO stage IIIA who is alive without any evidence of disease 10 years after treatment. The alternative method of measuring the depth of invasion of tumors in vulvar squamous cell carcinoma patients is a promising alternative that needs to be a subject of more extensive research before implementation.

The conventional measuring method was chosen mainly based on practical issues ${ }^{11}$; the adjacent dermal papilla can be found in all sites of the vulva, is not altered by variations in the depth of rete ridges, and the measurement is not significantly influenced by hyperkeratosis, tumor surface ulceration, or adjacent epithelial hyperplasia. Wilkinson et $a{ }^{16}$ considered different measuring methods in one of his first studies about microinvasive carcinomas of the vulva and states that the difficulty in measuring from the deepest rete ridge (the alternative method used in this study) is that the overlying epithelium at the site of the neoplasm may itself be neoplastic and would be a variable site of measurement. The problem of variability can be argued; in our study no cases with the invasive overlying epithelium were seen. No disadvantages are described about the conventional measuring method by Wilkinson; however, often it turns out to be difficult to choose the most adjacent superficial rete ridge. In some cases the rete ridge is far from the tumor, and logically it is not likely that the tumor will originate from a point that is far away. Maybe, this difficulty is one of the reasons for the recent findings of Abdel-Mesih et $a 1^{17}$; they showed that the interobserver reliability between 11 gynecologic-orientated pathologists for diagnosing vulvar squamous cell carcinoma as invasive is fair $($ Kappa $=0.24)$ and for measuring depth of invasion moderate $($ Kappa $=0.51)$. When using the conventional method, interpretation of the location of the most superficial dermal papilla varied among pathologists. Pathologists used a different measuring method, similar to those displayed in Figure 1, other than the conventional one in $0-39 \%$ of the cases for reasons not mentioned. The question arises that how reliable is the use of the alternative method in our study. The recognition of differentiated VIN, which was in the surrounding of the tumor in 50$58 \%$ of the cases, is another difficulty in this study. We showed in one of our earlier studies that the interobserver agreement on the diagnosis of differentiated VIN is not high (Kappa 0.08-0.54); ${ }^{18}$ therefore, it may be more difficult to recognize the most adjacent rete ridge. 
When using the alternative measuring method, $19 \%$ of the patients were downstaged. This subgroup of patients showed more often a well-differentiated tumor, had less lymphovascular invasion, less recurrences, and a disease-specific survival of $100 \%$. In this group no groin recurrences were identified. Probably this subgroup of patients may be treated without groin surgery, with less morbidity as a result. In our study population, four inguinofemoral lymphadenectomy procedures and nine sentinel lymph nodeprocedures could have been prevented. Although the morbidity of the sentinel lymph node procedure is limited, it might be of great advantage to prevent any surgical procedure of the groins to save the sentinel lymph node procedure for a possible future de novo tumor at follow-up. One should keep in mind that $\sim 25 \%$ of the vulvar squamous cell carcinoma patients will develop local recurrences, requiring complete lymphadenectomy in case of an earlier sentinel lymph node procedure as part of the primary treatment.

There is a chance of $<1 \%$ of positive lymph nodes in patients with a depth of invasion of $<1 \mathrm{~mm}$ measured with the conventional measuring method. ${ }^{7,8,19}$ This is substantially lower compared with the $7 \%$ when the case with FIGO stage IIIA, which had a depth of invasion of $0.2 \mathrm{~mm}$ (instead of $3.5 \mathrm{~mm}$ ) with the alternative measuring method, would be included within the group of 13 cases that were downstaged from FIGO stage IB to IA. However, this single case showed only two solitary immunohistochemically detected tumor cells in the sentinel lymph node, and the patient is alive without any evidence of disease 10 years after treatment. Although the finding of the isolated tumor cells in the sentinel lymph node seems to be an important disadvantage of using the alternative measuring method, the value of this finding is questionable. In 2000, the sentinel lymph node procedure was introduced with ultrastaging and the use of immunohistochemistry as a routine procedure. This technique allows a more extensive pathological examination of the lymph nodes compared with that of the conventional lymph node dissection, which will result in an increase in the detection of small tumor deposits such as isolated tumor cells and micrometastases. ${ }^{20,21}$ In a study of van der Zee et $a l^{5}$ sentinel lymph nodes were examined by routine pathological examination, and only when no metastases were found, ultrastaging was performed. A total number of 163 positive nodes were detected, of which $95(58 \%)$ were detected by routine pathological examination and $68(42 \%)$ by ultrastaging. Oonk et $\mathrm{al}^{22}$ showed that the risk of nonsentinel node metastases increases with the size of the sentinel lymph node metastases; one of 24 patients (4\%) with isolated tumor cells had non-sentinel lymph node metastases. Furthermore, they showed that the prognosis of patients with a positive sentinel lymph node based on isolated tumor cells is similar to patients with a negative sentinel lymph node.,22 However, firm conclusions are difficult to draw because of the lack of power, and therefore Oonk et $a^{22}$ recommend additional groin treatment for all patients with vulvar SCC with sentinel lymph node metastases, regardless of the size of the lymph node metastases. Besides, the therapeutic effect of this procedure, which was part of the routine treatment, is undefined. More is known about the role of isolated tumor cells in patients with breast cancer. De Boer et $a l^{23}$ showed that isolated tumor cells or micrometastases in the sentinel lymph node were associated with a reduced 5-year disease-specific survival for women with favorable early-stage breast cancer who did not receive adjuvant hormonal therapy or chemotherapy. In patients with isolated tumor cells or micrometastases who did receive adjuvant therapy, disease-specific survival was improved. In the study of Pepels et al ${ }^{24}$ the relevance of isolated tumor cells with respect to the risk of regional recurrence is considered to be of uncertain significance, not supporting the routine use of axillary treatment (in contrast to recommendations in sentinel lymph node micrometastases). However, other large studies on isolated tumor cells in patients with breast cancer have not shown any effect on disease-specific survival. $^{25}$ An important issue when comparing vulvar squamous cell carcinoma patients with breast cancer patients is the difference of receiving adjuvant therapy. In vulvar squamous cell carcinoma patients, no adjuvant therapy is given (only radiotherapy in case of more than one intranodal groin lymph node metastasis or extranodal growth), whereas in breast cancer patients (neo)adjuvant systemic therapy and/ or locoregional radiation therapy is given in a substantial number of patients. This may result in the eradication of possible (micro)metastases. Another difference is the observation that a recurrence in the groin in a patient with vulvar squamous cell carcinoma is nearly always fatal and is an important reason to be reluctant in omitting treatment of the groin. Further study is needed to establish the prognostic significance of isolated tumor cells in sentinel lymph nodes of patients with vulvar squamous cell carcinoma.

In conclusion, using the alternative method for measuring the depth of invasion in vulvar squamous cell carcinoma, $19 \%$ of patients with a FIGO stage IB tumors might be treated less radically, resulting in less treatment-related morbidity. Only one patient with FIGO stage IIIA with microinvasive vulvar squamous cell carcinoma based on the alternative measuring method had isolated tumor cells in the sentinel lymph node. On the basis of our result, it seems reasonable to further explore the introduction of the alternative measuring method in a prospective study with a higher number of patients before implementation in daily clinical practice.

\section{Disclosure/conflict of interest}

The authors declare no conflict of interest. 


\section{References}

1 Schuurman MS, van den Einden LC, Massuger LF, et al. Trends in incidence and survival of Dutch women with vulvar squamous cell carcinoma. Eur J Cancer 2013;49:3872-3880.

2 Gaarenstroom KN, Kenter GG, Trimbos JB, et al. Postoperative complications after vulvectomy and inguinofemoral lymphadenectomy using separate groin incisions. Int J Gynecol Cancer 2003;13:522-527.

3 Hinten F, van den Einden LC, Hendriks JC, et al. Risk factors for short- and long-term complications after groin surgery in vulvar cancer. Br J Cancer 2011; 105:1279-1287.

4 Ansink A, van der Velden J. Surgical interventions for early squamous cell carcinoma of the vulva. Cochrane Database Syst Rev 2000;CD002036.

5 Van der Zee AG, Oonk MH, De Hullu JA, et al. Sentinel node dissection is safe in the treatment of early-stage vulvar cancer. J Clin Oncol 2008;26:884-889.

6 Magrina JF, Gonzalez-Bosquet J, Weaver AL, et al. Squamous cell carcinoma of the vulva stage IA: longterm results. Gynecol Oncol 2000;76:24-27.

7 Wilkinson EJ. Superficial invasive carcinoma of the vulva. Clin Obstet Gynecol 1985;28:188-195.

8 Yoder BJ, Rufforny I, Massoll NA, et al. vulvar squamous cell carcinoma: an analysis of tumor invasive characteristics and risk. Am J Surg Pathol 2008;32:765-772.

9 Hacker NF, Van der Velden J. Conservative management of early vulvar cancer. Cancer 1993;71:1673-1677.

10 Wilkinson EJ, Kneale B, Lynch PJ. Report of the ISSVD terminology committee. J Reprod Med 1986;31:973-974.

11 Preti M, Rouzier R, Mariani L, et al. Superficially invasive carcinoma of the vulva: diagnosis and treatment. Clin Obstet Gynecol 2005;48:862-868.

12 Kurzl R, Messerer D, Baltzer J, et al. Comparative morphometric study on the depth of invasion in vulvar carcinoma. Gynecol Oncol 1988;29:12-25.

13 Witkiewicz AK, Wright TC, Ferenczy A, et al. Carcinoma and other tumors of the cervix. In: Kurman R, Ellenson L, Ronnett B (eds). Blaustein's Pathology of the Female Genital Tract. Springer: New York, 2010, pp 254-295.

14 Wenig B. Neoplasms of the larynx, hypopharynx, and trachea. In: Schmitt W (ed). Atlas of Head and Neck Pathology, 2nd edn. Elsevier: Philadelphia, 2008, pp 439-526.
15 Pecorelli S. Revised FIGO staging for carcinoma of the vulva, cervix, and endometrium. Int J Gynaecol Obstet 2009;105:103-104.

16 Wilkinson EJ, Rico MJ, Pierson KK. Microinvasive carcinoma of the vulva. Int J Gynecol Pathol 1982; $1: 29-39$.

17 Abdel-Mesih A, Daya D, Onuma K, et al. Interobserver agreement for assessing invasion in stage 1A vulvar squamous cell carcinoma. Am J Surg Pathol 2013;37: 1336-1341.

18 van den Einden LC, de Hullu JA, Massuger LF, et al. Interobserver variability and the effect of education in the histopathological diagnosis of differentiated vulvar intraepithelial neoplasia. Mod Pathol 2013;26: 874-880.

19 Vernooij F, Sie-Go DM, Heintz AP. Lymph node recurrence following stage IA vulvar carcinoma: two cases and a short overview of literature. Int J Gynecol Cancer 2007;17:517-520.

20 Terada KY, Shimizu DM, Wong JH. Sentinel node dissection and ultrastaging in squamous cell cancer of the vulva. Gynecol Oncol 2000;76:40-44.

21 Robison K, Steinhoff MM, Granai CO, et al. Inguinal sentinel node dissection versus standard inguinal node dissection in patients with vulvar cancer: a comparison of the size of metastasis detected in inguinal lymph nodes. Gynecol Oncol 2006;101: 24-27.

22 Oonk MH, van Hemel BM, Hollema H, et al. Size of sentinel-node metastasis and chances of non-sentinelnode involvement and survival in early stage vulvar cancer: results from GROINSS-V, a multicentre observational study. Lancet Oncol 2010;11:646-652.

23 de Boer M, van Deurzen CH, van Dijck JA, et al. Micrometastases or isolated tumor cells and the outcome of breast cancer. N Engl J Med 2009;361:653-663.

24 Pepels MJ, de Boer M, Bult P, et al. Regional recurrence in breast cancer patients with sentinel node micrometastases and isolated tumor cells. Ann Surg 2012; 255:116-121.

25 Reed J, Rosman M, Verbanac KM, et al. Prognostic implications of isolated tumor cells and micrometastases in sentinel nodes of patients with invasive breast cancer: 10-year analysis of patients enrolled in the prospective East Carolina University/Anne Arundel Medical Center Sentinel Node Multicenter Study. J Am Coll Surg 2009;208:333-340. 